\title{
Financing of Research in Universities
}

\author{
John B. Macdonald *
}

Financing of research in universities has been in recent years a topic of study, a target for criticism, and a source of anxiety. A number of reports both federal and provincial have dealt with this subject. Three have been selected for partial review because of important similarities and what appear to be significant similar weaknesses in their policy proposals. They are the Bonneau-Corry Report on the Rationalization of University Research, ${ }^{1}$ the Report of the Senate Special Committee on Science Policy, chaired by the Honourable Maurice Lamontagne, ${ }^{2}$ and the Report of the Commission on Post-Secondary Education in Ontario. ${ }^{3}$ The critique is followed by an alternative approach to the funding of research in universities.

\section{The Bonneau-Corry Report}

The Bonneau-Corry report was commissioned by the Association of Universities and Colleges of Canada because of a conviction that while governments and governmental agencies were elaborating science policies of great relevance to the universities, the universities were not giving the subject of university research policy the attention it required. The inquiries by Bonneau and Corry led them to the conclusion that there is a conflict between two legitimate interests of universities and governments and that the conflict must lead to a compromise. The legitimate concern of government is "to account for expenditures of public money in something like specific terms." General appropriations for research, given the amounts of money now involved, need to be justified by category at a level of detail not customary in the past. Universities traditionally and legitimately have wished to allow each researcher to choose his research interests freely. Bonneau and Corry were convinced that this conflict demands a compromise and their report is addressed to the search for a workable solution.

Bonneau and Corry's premise is that the primary function of universities is to teach and that everything else is secondary. This leads them to the view that research which sustains teaching is part of the primary mission and should be distinguished from research which is unrelated to teaching. They advance the proposition that such a distinction is possible and, for their purposes, introduce the terms "reflective inquiry" and 'f'rontier research."

\footnotetext{
* John B. Macdonald, Executive Director, Council of Ontario Universities.
} 
"Reflective inquiry" is described as "an almost entirely intellectual activity." As Bonneau and Corry put it, "We are in the study or at the chalk board reflecting on the known knowledge, including the latest reports from the frontier." It is to work "not with the seeing eye or with the mind narrowly focused on minute analysis, but rather with the synthesizing mind, more concerned with breadth of view than with depth of specialization and minute analysis." Reflective inquiry is said to be vital for all good teaching because the breadth of its sweep enlarges the vision. Erudite scholarship, on the other hand, when focused on minutiae of ten has a stupefying effect.

"Frontier research" is described as the "digging up of new facts." It is heavily empirical based on experiment and observation, and the identification of phenomena by the use of the senses. It is the kind of activity particularly common to the sciences and for which various agencies provide grants. The authors assume that this kind of research can be carried out effectively in the absence of reflective inquiry. Their assumption can be supported by a review of the research proposals submitted to and awards made by most major granting agencies. Many projects are predominantly empirical and show little or no evidence of "reflective inquiry." Much of the published literature in many fields is commonly criticized by leading investigators because of its trivial nature. Harvey Brooks, for example, has estimated that not more than about five percent of the basic scientific research carried on in universities is truly outstanding.* 4 This common understanding helps to justify the distinction proposed by Bonneau and Corry between "frontier research" and "reflective inquiry" for much of the research activity in universities.**

* This is not an argument for limiting support to the top five percent. Much of the plodding investigation by the drones of science is essential as background for the most creative investigators. The question for both government and science is : How much ?

** A different view of the normal practice of science is developed by Thomas Kuhn.5 According to Kuhn 'normal science' is based upon the acceptance of one or more past scientific accomplishments which provide the foundation for further practice. Such accomplishments are designated as paradigms when they are sufficiently persuasive to attract a group of adherents and sufficiently open-ended to expose a variety of problems for the practitioners to resolve in the light of the accepted achievement. In the absence of a paradigm, all "facts" in a field seem equally relevant and fact-finding has a characteristic randomness. "The Baconian 'histories' of heat, color, wind, mining, and so on are filled with information, some of it recondite. But they juxtapose facts that will later prove revealing (e.g., heating by mixture) with others (e.g., the warmth of dung heaps) that will, for some time, remain too complex to be integrated with theory at all." When the scientist can take a paradigm for granted he no longer has to build from first principles - that task is left to the writer of text books. Rather, his research will relate to the subtleties derived from the acceptance of the paradigm and his communications will be addressed to the small circle of specialists who share the paradigm and are concerned with its consequences. Thus, "mopping-up operations are what engage most scientists throughout their careers." Normal science (as opposed to scientific revolutions) is concerned with elaborating and articulating the consequence of paradigms: it is not concerned with seeking new phenomena or inventing new theories. Breakthroughs or scientific revolutions result from the inadvertent emergence of conflict between fact and theory arising in the normal course of efforts to elaborate or refine the consequences of a paradigm. They are generally resisted by scientists. 
The authors go too far however when they state that many faculty members are "very good at frontier research" and indifferent at reflective inquiry. The good scientist will reject Bonneau and Corry's claim. One of the almost inevitable attributes of a scientist capable of very good frontier research is a capacity for reflective inquiry. Among other things, such thought determines the selection of research projects which usually bears heavily on the scientific significance of the results that are obtained. Technically skillful atention to inconsequential problems does not constitute good frontier research. At best, it represents the filling in of details; at worst, the investigation of artifacts.

The authors also conclude that frontier research, unlike reflective.inquiry, does not contribute vitally to teaching, at least in many disciplines. They offer no suggestions about which disciplines are exceptions or how they are to be distinguished.

The Bonneau-Corry conclusions concerning funding are based on the above assumptions. Since reflective inquiry is closely related to teaching, it should be supported for the most part within the teaching budget. Since the main need of the reflective inquirer is time, this is equivalent to saying that his salary should cover not only his teaching responsibilities, but also a portion of his time which he can use for reflective inquiry. There are occasionally other minor costs - an assistant, travel to reach important library resources, office supplies. These should be available on application either from a designated university budget or from the Canada Council.

Frontier research, on the other hand, should be supported by external agencies, notably the three federal Councils, NRC, MRC, and Canada Council. Bonneau and Corry agree with other writers that the sponsors of frontier research should pay the indirect costs associated with the research. Unlike others, they argue that the indirect costs should include a portion of the salary of investigators. Specifically, they recommend that indirect costs be set at $45 \%$ as against earlier estimates in other reports placing indirect costs at $30 \%$ to $35 \%$, exclusive of faculty salaries. ${ }^{6-7}$ They suggest that the indirect cost payment should be paid into the general revenue of universities and should not be paid as supplements to salaries of investigators. The reasons put forward for including a portion of faculty salaries in indirect costs were, first, that frontier research does not always support teaching. Second, because provincial governments may think certain research is irrelevant, they won't want to pay the salary costs associated with it.

These reasons are not persuasive. The identification of that research which is related to teaching is not operatively practical and a division of responsibility for research funding between federal and provincial governments based on this distinction would run into endless argument and conflict unlikely to be resolved to the satisfaction of either funding party, let alone the universities. The second reason seeks to escape from a problem rather than deal with it. Is there merit to provincial governments concerns about irrelevance? Universities should face such charges directly. If the universities are on sound ground it should be possible to persuade governments that what they are doing makes sense. If they are not always on sound ground (and that view is part of the theme 
of Bonneau and Corry) then they should change. Simply shifting more of the responsibility to the federal government won't solve the problem.

A major part of the Bonneau-Corry report deals with the basis of making choices concerning the research which is to be undertaken in universities. They describe a complex system of committees in an interlocking hierarchy involving individual universities, consortia, provinces and the federal government. Each level is asked to deal with policy, i.e., institutional or governmental objectives in pursuing research. This so-called rationalization process is only indirectly related to the financing of research. It determines and limits the freedom of individuals to apply to funding agencies for the support of their projects. As such it is bound to have a stifling effect on creative imagination, depending as it does on the wisdom of committees to catalogue in advance all the areas in which it is sensible for a university or the nation to conduct research. It would be dampening and discouraging in another way also. Academics with ability and dedication to their field will be reluctant to face the series of hurdles which must be jumped before their project has a chance to be judged on its own merits. If they are good they will be tempted to seek and find a more salubrious research climate.

If one accepts the Bonneau-Corry premise that teaching is primary, it would be reasonable to say that good dedicated researchers should be allowed to go because their loyalty is to research, or the republic of science rather than to the university and its goals. If, on the other hand, teaching and research are both viewed as central to the purposes of a university, then the good researcher committed to both teaching and research can be dedicated to the idea of a university but unwilling to serve in an institution that does not allow for the best research proposals to be chosen on their merits. The loss of such persons would be serious for a university.

Returning to the distinctions between reflective inquiry and frontier research and the differences in funding them, one must ask what the authors hoped to accomplish by their proposals. They list their criticisms of the present situation and by implication it is to the correction of these presumed faults that their recommendations are directed. The criticisms are that:

1. No university has gone far in setting its objectives in research.

2. Graduate work has been started in a number of universities not yet qualified to offer it.

3. Nearly all universities have had too low standards of admission to graduate school, resulting in a high rate of dropouts.

4. There has been considerable duplication of expensive equipment.

5. Humanists, in particular, have suffered in advancement in rank and in salaries because in general they have not been engaged in frontier research.

These are sweeping indictments for which no evidence is offered. Their conclusions may or may not be correct. Was the dropout rate of graduate students higher 
in the booming Sixties than in earlier years? Has the cost of duplicating equipment been greater than the very real costs of not duplicating it ? Have humanists really had slower advancement in rank and salary than scientits?

The authors were conscious of the fact that their criticisms were offered without evidence and were careful to explain that the criticisms represented widely held views among those whom they consulted. The systematic gathering of evidence on these difficult questions was apparently beyond the Commission's resources. Evidence is available however on some of the points. In Ontario, for example, the evidence from a system of appraisals of graduate programmes over the past five years has shown that in a number of cases programmes were judged by the appraisers not to meet satisfactory minimum standards. ${ }^{8}$ In the early stages of assessing the need for graduate programmes in Ontario universities, a process involving some comparisons of quality, the consultants have, in some cases, reported large differences in quality.

On the question of treatment of humanists the evidence could be readily gathered. In one case (UBC) in the Sixties, a comparison of salaries and rank of humanists as against other groups of university faculty did not disclose discriminatory practice. On this point, a more general examination of the evidence is needed. If the commonly repeated claim that humanists have been at a disadvantage in terms of salary and rank proves to be true, it deserves correction. If it is a myth, it should be exposed.

Most persons would agree that too many universities entered graduate work too soon during the Sixties. If that is accepted, would the Bonneau-Corry proposals change that situation or prevent future recurrences? It is difficult to see how they would. In criticizing the general lack of evidence to support the Bonneau-Corry contention, the intention is not to suggest that their conclusions are wrong. They may well be right but it is important to know the facts because these assumptions are commonly held and are likely to influence policy. Their repetition by Bonneau and Corry makes the need for evidence more urgent.

\section{The Lamontagne Report}

The Lamontagne Report in its view of universities and university research has much in common with the Bonneau-Corry Report. It argues that the primary role of universities is teaching and that research is secondary. It claims, without evidence, that universities have based their remuneration and promotions too exclusively on basic research performance. The Report distinguishes between basic research and "research on the existing stock of knowledge" which is related to teaching. Like Bonneau and Corry, the Senators recommend that the latter be funded out of general university revenues as part of the education budget. The Canadian government, on the other hand, would be responsible for funding basic research in universities. The three Councils, NRC, MRC, and Canada Council, would be reorganized as granting Foundations to meet this responsibility. They would be expected to meet the full direct and indirect costs (exclusive of faculty salaries) 
associated with the research which they support. Applied or mission-oriented research would be supported mainly by departments and agencies of the federal government other than the granting Foundations.

The universities, however, would be expected to concentrate mainly on basic rather than applied research. They should, according to the Senate Committee, limit themselves mostly to projects requiring only one or two top scientists and a few assistants. Consequently, the Committee makes no mention of the idea of universities as such developing their own internal policies concerning research priorities. They nevertheless state that it is not necessary for all universities to be involved in basic research although they do not suggest that any institutions should be ineligible for grants.

Finally the Committee appears ambivalent about the basis for approval of research proposals. At one point it argues for quality rather than quantity and the support of applicants representing excellence as judged against international quality standards. At another point it argues for limiting support to projects which are relevant to the Canadian scene, that is, areas where applied research and development are also being done in Canada. This latter recommendation is difficult to understand, since the Committee defines such basic research or curiosity-oriented research as research in which "the problems cannot be defined by persons outside the discipline and the solutions are usually completely restricted to the framework of abstract concepts within the discipline." How then can it be determined that such research is in an area relevant to the Canadian scene and in which application is being sought?

\section{The Report of the Commission on Post-Secondary Education in Ontario}

The Commission on Post-Secondary Education in Ontario examined the current methods of supporting universities in Ontario and declared them to be unsatisfactory for several reasons. Since 1966 the government has determined its subventions to universities by a formula based on the number of students and the programmes in which they are registered. More expensive programmes carry a higher weighted value than relatively inexpensive programmes. The arts and science undergraduate students carry a unit weights of 1 and $\mathrm{PhD}$ students a weight of 6 units. Income is determined by the value of the unit, adjusted annually.

The Commission claimed that the system has several shortcomings.

1) It does not encourage coordination. Graduate programmes proliferated according to the Commission without adequate attention to the need for quality, specialization, responsiveness to regional wants and economy.

2) The formula has a steering effect, encouraging universities to design programmes to maximize their incomes rather than to realize institutionally determined pedagogical goals. 
3) The student count has been a proxy for all costs including both instructional costs and research costs. It has therefore tended to inhibit a clear assessment of society's research needs.

4) Indiscriminate support of research in all universities has hampered the development of excellence.

5) Funding of research on the basis of student numbers makes it difficult to ensure that "students who need subsidies" receive them. Presumably what is meant by the Commissioners is that educational programmes may be short-changed if funds are designated for research.

These claims are not all easy to understand and accept. The formula was not devised as a method of encouraging coordination but as a method of allocating funds on an objective basis. It is not surprising therefore that it has not accomplished an unrelated objective. Graduate programmes did proliferate but no more in Ontario than in other provinces where formula financing was not used. The formula is said to have had a steering effect and no doubt this has been the case. However, it is interesting to note that in the provincially-assisted universities in Ontario, the growth rate of graduate studies (for which the formula paid high subsidies) was the same as the undergraduate growth rate throughout the decade of the Sixties. Graduate students accounted for $11.5 \%$ of total full-time enrolment in 1960-61 and 12\% in 1970-71 ${ }^{\circ}$. The formula was introduced in 1967 without evidence of a subsequent increase in the rate of growth of graduate enrolments. Moreover, the compound annual growth rate for graduate enrolment in Ontario from 1964-65 to $1969-70$ was $16.7 \%$ whereas the comparable figure for the rest of Canada was $26.6 \%$. Graduate enrolment for the five year period more than doubled in Ontario but more than trebled in the rest of Canada ${ }^{10}$. These facts do not negate the claim that steering effects have been introduced but they do suggest that other factors may have been more. important. The conviction of universities and governments that graduate studies needed to be encouraged, the status associated with involvement in graduate work, the reward system within the universities, all encouraged graduate expansion.

The meaning of the claim that indiscriminate support of research in all universities hampered the development of excellence is obscure. Was the support indiscriminate ? Provincial funds paid the salaries of faculty but otherwise little of it found its way into the direct support of research (Table 1). Has indiscriminate support of teaching hampered the development of excellence ? Are the commissioners assuming that selective choices by government or its agent about which research should be supported will have a better chance of encouraging excellence than if the choices are left to the universities?

The modification proposed as a panacea for these claimed weaknesses is to calculate the formula support on the basis of two independent variables - instructional 
costs and research costs. The instructional cost would continue to be based on student numbers, and would include costs of research vitally associated with teaching. Research not intimately related to teaching would be separately funded on a three to five-year basis following quality assessment. One of the keys to this approach, as in the case of the Bonneau-Corry recommendations, is the ability to distinguish between research which is important to teaching and that which is not. The Commissioners acknowledge the difficulty. They suggest that the separately funded research should be that which is heavily capitalized and involves non-teaching functions. Yet they exclude from this category the scholarly work of humanists while counting libraries as examples of heavy capitalization. This example of contradiction merely serves to illustrate the operational impracticability of the separation.

The Commissioners, while claiming that their proposals would help to correct what they see as weaknesses in the present system, fail to explain just how this would be accomplished. They do however call for systematic planning of research within and between institutions, within the provincial government, and at the federal level. Quality assessment would presumably take place at the provincial level and be superimposed on the quality assessment now imposed at the federal level by the granting agencies. One can only shudder at the bureaucratic potentialities for evaluating the quality of research in each university, taken as a whole and across all fields, as a basis for determining global research support. It seems not far-fetched to suggest that such assessment would be based on provincial research policies, whether or not they coincided with those of universities or the federal government.

This is not to suggest that quality assessment is not needed or that it is now performed in a satisfactory way. Stiffer assessment by federal agencies has been called for in the Macdonald Report ${ }^{\text {, }}$, the Lamontagne Report ${ }^{2}$ and the Bonneau-Corry Report ${ }^{1}$. Surely, however, the question of quality should be decided for each research proposal and not by some summation and averaging of quality for a whole institution.

The conclusions in common in all three of the above Reports are that :

1) Theaching is primary; research is secondary.

2) Some research is related to teaching; some is not, and the two can be distingushed.

3) The university, through its general revenues obtained from the province, should pay for research related to teaching.

4) The federal government, through its granting Councils, should pay for research not related directly to teaching.

5) The sponsors of research should pay both direct and indirect costs.

The main premises are wrong. It is not helpful to assume that teaching is primary and research is secondary. Both are essential to the idea of a university as that idea has 
evolved. An institution engaged in teaching but not research could be a valuable institution but it would not be a university. Conversely, a research institute not engaged in teaching would not be a university. Since both are essential no purpose is served in attempting to set their relative priorities. This is not to say that the relative emphasis on each is not a proper question of policy. Indeed it is, but it can be settled very differently in different universities.

The second error is in assuming that an operational distinction can be made between research related to teaching and research not related to teaching. It is simply not true to suggest that reflective inquiry is vital to teaching and that frontier research is not. The reason is that it is not characteristic of frontier research that it excludes reflective inquiry. Quite the contrary, good frontier research is based on reflective inquiry. It is this activity which leads to the significant or critical experiment. Research is not the mere collection of disconnected facts. The heart of scientific endeavor is the arrangement of facts, the continuing effort to find the truth behind the appearances of things and the truth is not merely common sense conclusions. Often it is very uncommon sense. Bronowski has said, "the truth we are looking for in science is something at the center of things, it has to fit the facts, but it has to be much deeper, more coherent than the mere facts." 11

As a single example nothing could be much more important to the teaching of biology than what has been learned about the genetic code. Could it possibly be argued that the frontier research on DNA by Watson and Crick which disclosed the code made less of a contribution to teaching because it involved precise $\mathrm{x}$-ray diffraction observations and measurements? The point is simply this. Research and teaching in the university are entwined and it is not possible in advance to predict which research will influence, indeed revolutionize, teaching.

The proposed separation of provincial funding of research and teaching would not solve the problems that it is intended to solve. It would not provide graduate planning. It would simply substitute one kind of steering effect in the formula for another kind. The separation would not produce an assessment of society's research needs, though it might tend to create a preoccupation with the political view of provincial research needs. The separation would not enhance the quality of research by imposing a new bureaucracy to evaluate what is already being evaluated. It would not prevent excess expenditures on research by universities. It might, in fact, aggravate such a tendency if the result could be expected to generate more provincial support.

\section{An alternative proposal}

There is an alternative and its origins were presented in a fourth report which pre-dated the three which have just been reviewed. It was Report No. 7 of the Science Council and Canada Council on the Role of the Federal Government in Support of Research in Canadian Universities. ${ }^{6}$ 
The alternative approach is based on the concept of a partnership involving the universities, the provincial governments and the federal government. Each of the partners has its own purposes in relation to university research and the financial arrangements need to serve the purposes of all the partners.*

Universities are both teaching and research institutions. Traditionally, they have favoured basic research, but in recent years have taken an increasing interest in applied research, especially in the professional schools. The universities conduct research for several reasons. They are society's principal instrument for continuing the culturallyimportant task of seeking new knowledge. They are a source of expertise for the solution of practical problems and for making contributions to the attainment of societal goals. Universities also conduct research because it enhances the quality of teaching. Teaching founded on research will engender a spirit of inquiry and enhance the ability to reach critical judgments. These are central to the teaching role of the university. Finally, universities engage in research because it is a necessary part of the task of training manpower to conduct research, whether for renewal of universities or to meet the needs of government, business, and industry.

While all universities must be engaged in research, their individual roles may vary greatly. Some may limit their research principally or even entirely to what Bonneau and Corry have called reflective inquiry. As recently as $1965-6$, fifteen universities in Canada received no income for sponsored, assisted or contracted research. ${ }^{6}$ Some universities, on the other hand, may commit a great deal of their effort to research requiring financial support. In 1965-6, for example, five Canadian universities received over 50\% of the total funds dispersed for university research. Most universities have research activities between these two extremes.

Universities ought also to be committed to the principle that worthwhile research ideas may originate in any discipline They should be prepared to provide a home for such research regardless of the field, subject to careful assessment being made of the merits of the proposal and the ability of the applicant.

The federal government, as the second partner, has its own interests to be served. The federal government is not interested in research as a goal in itself. Its concern is with the contribution research can make to the attainment of societal goals. The goals may be better health, cleaner cities, increased agricultural production, etc. The question for government is how can research help achieve the goals.

Among the goals of the federal government is the maintenance of a strong network of universities. This is an objective of national governments throughout the world. In Canada, the federal government contributes directly to the strengthening of universities through its support of research within them. Its main decision must be how much

* The financial arrangements dealt with here exclude capital funding such as buildings and libraries. Proposals concerning these items are included in the Macdonald Report. ${ }^{6}$ 
money it will devote to this purpose. The Lamontagne Committee, noting that $23 \%$ of Canada's research effort is in the field of basic research, proposed that that percentage be reduced to $10 \%$ by 1980 . Since the committee recommended growth in total Research and Development from about $1.3 \%$ of GNP (1967) to $2.5 \%$ in 1980 , there would remain room for continuing growth of basic research from $\$ 205$ million in 1967 to $\$ 475$ million in 1980, according to their proposals.

Once the government determines the amount of money it is prepared to devote to university research, and consistent with its commitment to a strong network of universities, it should adopt the following policies :

1) It should be prepared to entertain applications in any field while allocating its money for different fields with an eye to maintaining a reasonable balance of research activity within the universities.

2) It should reform its procedures for assessing merit to make the judgments more rigorous and it should award grants within a field strictly on merit.

3) It should pay the full direct and indirect costs of research which it supports (exclusive of faculty salaries).

The importance of paying indirect costs needs emphasis. If they are not paid by the sponsor, the university is forced to allocate its general revenues to this purpose, thus distorting its own internal priorities and very likely drawing on money which should be allocated to teaching. Not only is the university frustrated but so also will be the provincial government which puts up the funds for general university support. If, on the other hand, full direct and indirect costs are paid by the grantor, the fiscal effect is neutral.

Quite aside from its support of research intended to help maintain a strong network of universities, the federal government will be interested in research in a host of areas important to governmental objectives. Whatever these goals, the government can, for purposes now outside of the university, seek to procure from the university the research which it requires. This is generally done through a contract arrangement. The research can be solicited by government or proposed by the university on the basis of its view of the research needed to achieve some national goal. Whichever way it is originated, it calls for careful negotiation to ensure that the goals of both parties are served.*

Turning finally to the role of the provincial governments, it can be said that their objectives parallel those of the federal government, i.e., to have strong universities and to procure research important to the attainment of provincial goals. Here, however, the similarity ends. The provincial government has a broader and more direct concern for the universities than has the federal government. It supports the educational functions and provides for the faculty required for both teaching and research. Its concern with

* The conditions which bear on the appropriateness of university participation in such research are dealt with in the Macdonald Report, Pp. $10,11{ }^{6}$ 
research relates to the policies of the university as a whole. Its support is given to the university to be expended as the university determines, whereas the federal government gives its funds in trust to the university for the support of specific research projects and identified grantees.

If the federal government should adopt the policy of paying full direct and indirect costs of the research which it supports, the provincial contribution to federally supported research (excluding capital) would be limited to paying for the time of faculty members. What would be the stance of the provinces under such circumstances ?

The first point to observe is that a substantial part of the provincial subvention tied to graduate education actually goes to cover the indirect costs of research. In Ontario, for example, the provincial income related to graduate enrolments is currently about $\$ 90$ million. Funded research amounts to about $\$ 60$ million. The indirect cost of funded research based on a rate of $35 \%$ is about $\$ 21$ million. If this amount was paid by the federal government to the universities, the first thing the Ontario government would wish to do would be to lower the weights for graduate students by an average of nearly $25 \%$ so that the universities would not be reimbursed twice.

As matters now stand, each university receives more or less equitable treatment for its undergraduate programmes but some, mainly older universities, receive large additional sums (tied to graduate enrolments) which allow them to devote a disproportionately larger amount of their total faculty time to research than other mainly younger and smaller institutions. This is because the values attached to graduate students are a proxy for the combination of the costs of graduate instruction and the provincial contribution to research. The research subvention is the larger of the two and, in fact, represents the major commitment of resources, especially faculty time, which must be made before the university is ready to accept graduate students (Table 1 ).

It seems clear that the use of graduate counts is a poor proxy because it means that the only way a university can get research time covered in excess of that provided by the uniform treatment of undergraduates' programmes is by accepting graduate students. It is reasonable to assume therefore that provincial governments will wish to discontinue the heavy weights attached to graduate students and substitute weights related to research performance plus modest weights to recognize the incremental costs of graduate instruction.

The basis for formula weighting related to research could be either to recognize those universities where research is actively pursued assuming that it will continue to be unevenly distributed among universities; or to deliberately set out to create certain research universities. Given the fact that a number of universities already have international recognition for their research, the former choice would be more likely.

What sort of a formula could be devised to reflect research activity ? The first requirement would be that it recognize research in all fields as part of the university's 
commitment to the support of critical inquiry. Secondly, the formula should support commitment to research of high quality. Third, the formula should recognize the amount of research in terms of some estimate of faculty time. Fourthly, the formula should recognize only extended requirements of faculty time. The faculty time for Bonneau-Corry's reflective inquiry or for modest research commitments of faculty would be covered in the undergraduate formula which assumes, say, nine hours of teaching and the remainder of the week available for teaching preparation and other purposes including research. Finally, the formula should give stable support over a period of about five years.

The basic cost to be covered in a research formula would be faculty time. The unit representing this cost could be known as a research income unit. It would be calculated on the basis of one RIU entitlement for so many dollars of sponsored research income. Different kinds of research have different costs. On the average, for example, the cost of providing a full-time researcher in chemistry with his needs (equipment, supplies, services and assistants) would be a good deal more than for a full-time researcher in philosophy.* Conversely, the amount of faculty time required for equal size grants would be larger for the philosopher than for the chemist. This principle could be incorporated into a formula. The formula might recognize, say, three categories of research sciences, social sciences and humanities, and allow one RIU for each $\$ 50,000$ of income for sponsored research in the sciences, one RIU for each $\$ 30,000$ in the social sciences, and one RIU for each $\$ 10,000$ in the humanities (Table 2).

The figures are entirely hypothetical. In practice it would be necessary to derive a set of research categories, corresponding RIU entitlements, and RIU values which, to begin with, would yield for each university approximately the same income it receives under its present formula.** Otherwise, the new formula would produce serious perturbations in universities' income. While universities would not experience immediate changes in provincial income, the new formula, over time, would reflect changes in research activity.

The assurance of quality should be gained through reform in the adjudication of individual research proposals by granting agencies of the federal government. Such reform has been frequently called for. Peer judgment is important but the peers should be drawn from government and industry as well as the universities. Review committees should not be overloaded, should be provided with good staff work and independent refereeing. The review committee members should serve for limited terms and should not have a voice in the choice of their successors.

* In the AUCC Cost Studies Arts faculty reported $24 \%$ of their time devoted to graduate supervision and research. The figure for Sciences faculty was $36 \%$. However, in the same year (1967-68) Arts research income from federal sources was only $\$ 5,157,000$ whereas Science research income was $\$ 60,731,000 .^{6}$

** Table 3 shows application of the principles to the actual enrolments and entitlements in one Ontario university. Using different values for graduate student weighting and for RIU entitlement, the model generates approximately the same income now received by the university. 
As mentioned, the research formula should provide stable support for five years; adjusted annually to offset rising costs. Thus, for each quinquennium the formula would be related to average annual faculty time devoted to funded research over the past five years. This would prevent much of the short run steering effect said to be characteristic of present formulae.

At first glance it might appear that the proposal would commit the provincial government to paying at a level determined by federal decisions about grants. This is not so however because the province would determine the value attached to the research income unit and could set it at whatever level it chose. The provincial concerns in supporting research by formula would be to control the overall level of support and to be satisfied that the basis of judgment about which research should be supported was as expert as possible. It seems likely that the provincial government, while wanting to see the job done well, would not want to do it itself.

A formula of the kind proposed might go a long way towards meeting some of government's concerns about the inadequacy of the present formula. It might for the universities relate their income more realistically to their costs and allow institutions to develop research competence without being pressed to offer graduate programmes. It would not solve the problems of planning and coordinating graduate activity. Other mechanisms are required for that purpose.

The proposal, it will be noted, relates RIU income to sponsored research. Contracted research should be included under this rubric provided that it is research for which the university is not reimbursed for faculty salaries. If the contract research requires leave-of-absence or released time of faculty which is reimbursed, then it should be excluded from the calculation of RIU income.

Certain other exclusions should be made where there are special arrangements such as those for Negotiated Development Grants. In these cases, for special reasons, faculty salaries may be paid for a period of time by the sponsoring Council. If the university has the relevant salaries paid directly by the federal agency, it obviously should not receive RIU entitlement related to such research. However since the university is expected to pay the salaries after a specified number of years, the negotiations leading to the award of such grants should include provincial officials as well as the university and the federal agency.

Finally, a word should be said about research relevance from the standpoint of the provincial government. As with the federal government, the two concerns are to see that the amounts available are appropriate and that only research and researchers of high quality are supported. These are the policies which will help ensure strong universities and it is in seeking and maintaining these objectives that relevance is to be found. Beyond this requirement, if the provincial governments have research needs to serve their varied purposes, they can negotiate to procure such research from university groups, on the basis that the department of government involved agrees to pay the full cost. 
TABLE 1

Approximate Provincial Contributions to Research in Canadian Universities for the Year 1966-67, compared to the Total Ordinary Expenditures and the Assisted Research Income of the Universities *

Item

Amount

\$' 000,000

Provincial Contributions to Research

1. Assisted research funds from provincial government

2. Direct research expenditures from the universities general revenue

3. Research component of library acquisitions (a)

4. Research component of computing centres

5. Staff salaries allocated to research

6. Indirect Costs of Research :

In support of assisted research expenditures

In support of items 2,3 and 4

In support of staff salaries, item 5

7. Support of graduate instruction

8. Graduate student aid

Total Ordinary Expenditures

Assisted Research Funds from Non-provincial Sources

1. From federal sources (including graduate student aid)

2. From foundations, etc.

TABLE 2

A Hypothetical Model for a New Formula Based Partly on Student Counts and Partly on Sponsored Research Income

\section{PRESENT METHOD}

Undergraduate formula income

$\$ 7,000,000$

Graduate formula income

No. of graduate students

Average weight

BIU value

$\$ 1800$

Income

$$
\$ 3,002,400
$$

(a) Library operating costs are treated as part of the indirect costs of item 6 .

* Source - Macdonald Report, p. 50. ${ }^{6}$ 
Sponsored research income

Total income

NEW METHOD

Undergraduate formula income

Graduate formula income

No. of graduate students

Average weight per student

BIU value

Income

Sponsored research incomes

Sciences

$1,600,000$

Social sciences 390,000

Humanities 110,000

Total

Indirect $(35 \%)$
$\$ 2,100,000$

$\$ 12,002,400$

$\$ 7,000,000$

417

1.5

$\$ 1800$

$\$ 1,126,000$

$\$ 2,100,000$

$\$ 735,000$

Research formula income

Entitlement

1 RIU per 50,000

sciences income 32 RIU

1 RIU per 30,000

soc. sci. income $13 \mathrm{RIU}$

1 RIU per 10,000

humanities income $11 \mathrm{RIU}$

Total 56 RIU

Unit value - $\$ 20,000$

$(56 \times \$ 20,000)$

$\$ 1,120,000$

Total income

$\$ 12,081,000$ 


\section{TABLE 3}

\section{A Model for a New Formula Based Partly on Students Counts and Partly on Sponsored Research Income}

PRESENT METHOD using actual enrolments and entitlements in an Ontario university Undergraduate formula income $\$ 18,900,000$

Graduate formula income

No. of graduate students 750

Average weight

BIU value $\$ 1800$

Income

$\$ 5,400,000$

Sponsored research income

$\$ 2,500,000$

Total income

$\$ 26,800,000$

\section{NEW METHOD}

Undergraduate formula income

Graduate formula income

No. of graduate students 750

Average weight per student

BIU value

Income

Sponsored research income

$\begin{array}{ll}\text { Sciences } & \$ 2,100,000 \\ \text { Social sciences } & \$ 300,000 \\ \text { Humanities } & \$ 100,000\end{array}$

Total

$$
\begin{array}{r}
\$ 2,500,000 \\
\$ \quad 875,000
\end{array}
$$

Indirect $(35 \%)$

Research formula income

\section{Entitlement}

1 RIU per 30,000 sciences income 70 RIU

1 RIU per 15,000 soc. sci. income 20 RIU

1 RIU per 10,000 humanities income $10 \mathrm{RIU}$

Total

Unit value - $\$ 20,000$

Research formula income $(100 \times \$ 20,000) \quad \$ 2,000,000$

Total income 
Notes

1. Bonneau, L. and Corry, J.A. Quest for the Optimum: Research Policies in the Universities of Canada. Association of Universities and Colleges of Canada, Ottawa, 1972.

2. Lamontagne, M. et al. A Science Policy for Canada, Vol. 2. Information Canada, Ottawa, 1972.

3. Davis, D.O. et al. The Learning Society: Report of the Commission on Post-Secondary Education. Ministry of Government Services, Toronto, 1972.

4. Basic Research and National Goals. U.S. Government Printing Office, 1965.

5. Kuhn, Thomas G. The Structure of Scientific Revolutions. The University of Chicago Press, Chicago, 1962.

6. Macdonald, John B. et al. The Role of the Federal Government in Support of Research in Canadian Universities. Information Canada, Ottawa, 1969.

7. Bladen, V.W. et al. Financing Higber Education in Canada. University of Toronto Press, Toronto, 1965.

8. Ontario Council on Graduates Studies. The First Three Years of Appraisal of Graduate Programmes. 1970.

9. Porter, J. et al. "Towards 2000". McClelland \& Stewart Limited, Toronto, 1971.

10. Committee of Presidents of Universities of Ontario. Fourth Annual Review, 1969-70.

11. Bronowski, J. "A Moral for an Age of Plenty" in Saturday Evening Post, Issue 233, November $12,1960$. 